- Survey of career aspirations and development needs of doctors working in SAS grade or similar posts;

- Holding networking/educational events for SAS doctors;

- Producing a training and development framework for doctors working in SAS grade or similar roles who wish to progress in their careers.

Results All elements of the project have been achieved and the Training and Development Framework was launched in May 2019. Details of the mapping, the survey of development needs and the educational events will be shared. The project has benefited hugely from collaborative working with colleagues in Cheshire and Merseyside, who had already developed and implemented a Training and Development Programme for SAS doctors in their region.

Conclusion It was evident that providing the opportunity for SAS doctors to network with colleagues from other hospices and palliative care teams was particularly valuable, and has led on to the development of peer-led initiatives such as a Medical Directors Forum and a WhatsApp group. Further work to embed the Training and Development Framework and further support SAS doctor development in the region is currently being planned.

\section{P-51 IMPROVING CONFIDENCE IN COMPLETING RESPECT FORMS}

Jillian Wall, David Jones. University Hospitals of Derby and Burton NHS Trust, Derby, UK

10.1136/bmjspcare-2019-HUKNC.75

ReSPECT (Recommended Summary Plan for Emergency Care and Treatment) forms were introduced in Royal Derby Hospital a year ago. ReSPECT prompts clinicians to record more than just 'CPR' decisions, and should include personalised recommendations for patients' care in a future emergency. Anecdotally we felt junior doctors were uneasy with ReSPECT, and that forms were often 'partially completed', reducing their value to clinicians and patients alike. An audit of ReSPECT forms confirmed poor completion in some areas of documentation.

We organised a pilot teaching afternoon for Core Medical Trainees (CMTs), incorporating a Powerpoint presentation on ReSPECT, handouts of 'mock forms', and role play. In groups of six, alongside a facilitator, CMTs worked through vignettes of clinical scenarios requiring a ReSPECT form to be completed. Ground rules ensured confidentiality and opportunity for 'time out'.

CMTs engaged enthusiastically with scenarios - in each, one trainee acted as a patient/relative, and another as the doctor. Facilitators led reflection and learning pre- and post- each scenario. Ten trainees completed pre- and post- course questionnaires. Despite $80 \%$ reporting formal ReSPECT training previously, $30 \%$ and $20 \%$ rated themselves 'not confident' to have ReSPECT discussions with patients/relatives respectively, pre-course. None of the CMTs had completed online ReSPECT learning, and $60 \%$ reported informal 'on the job' learning.

Post-course none reported lack of confidence. The pre-/ post- course numbers who reported confident rose from $10 \%$ to $40 \%$, and from $10 \%$ to $50 \%$, in discussions with patients/ relatives respectively. Free text comments about the session were positive. A re-audit of ReSPECT forms is planned in the summer-it will be interesting to review whether forms completed by CMT doctors have changed.

We hope to embed similar ReSPECT teaching into junior doctor teaching in the trust at August change over, to allow all juniors practical 'simulated' experience in ReSPECT in addition to formal learning online and through presentations.

\section{P-52 END OF LIFE CHAMPIONS: EDUCATING AND EMPOWERING NURSES IN THE ACUTE HOSPITAL SETTING}

Mary Abbott, Victoria Brinkworth. University Hospitals Birmingham, Birmingham, West Midlands

10.1136/bmispcare-2019-HUKNC.76

Background/Aims The End of Life Care Strategy for England has highlighted the delivery of high-quality end of life care in hospitals as an area of priority (Department of Health, 2008). The National Survey of Bereaved People (ONS, 2016) found, however, that relatives of people who died in hospital rated overall quality of care significantly worse than any other place of death. Barriers to the provision of good end of life care have shown to include a lack of education and poor attitudes from nurses and clinicians (Gardiner, Cobb, Gott \& Ingleton, 2011).

We set up an End of Life Champions programme in 2017 aimed at empowering nursing staff to recognise end of life patients in a timely manner, and to feel confident in providing good, holistic end of life care to patients and their families in the ward setting.

Methods A two-day course was provided which covered a variety of areas surrounding end of life care. Delivery methods consisted of Powerpoint slides, group-work, and scenarios. The palliative care team then went on to assist the champions to take action in improving end of life care in their clinical areas.

Results Each champion completed a pre- and post-study day evaluation based on their confidence levels. Results showed a significant improvement in each session topic ranging from $13 \%$ to $36 \%$. Comments from some of the champions stated they found the course had given them a whole new perspective on how to approach end of life care, and also that they now felt empowered to challenge poor practice.

Conclusions Educating and supporting nurses in the acute hospital setting has been found to lead to increased levels of confidence and to actively improve care in their clinical areas. This thus enables translation of UK policy into practice. The end of life champions' work is being extended across all hospital sites and is ongoing.

\section{P-53 TEN MINUTE SHARING AND LEARNING}

Joanne Schofield, Sonia Bates. Prince of Wales Hospice, Pontefract, UK

\subsection{6/bmjspcare-2019-HUKNC.77}

Without doubt one of the biggest challenges faced by hospices is providing education to their staff. While we do provide internal study days, we wanted to offer ongoing education alongside. We trialled ten-minutes sharing and learning sessions after lunchtime handovers to offer education in bite-sized chunks, to either enhance knowledge and skills or to promote awareness, with the aim of improving standards of patient 
care. Topics ranged from: symptom management, oncological emergencies, staff wellbeing, nutrition, catheter care, pressure ulcer management, safe use of equipment, learning disabilities and wheelchair training, to mention just a few.

Over time members of the team have taken turns delivering sessions, particularly those who undertake additional link worker roles. Staff have been encouraged to share skills and knowledge gained while attending external study days. The sessions have been running for a year and have evolved during this time. We have reviewed and adapted the sessions to meet the challenges we have encountered.

Colleagues from the multi-disciplinary team, such as our physiotherapist and social worker have undertaken education pertinent to their roles. This has resulted in better understanding of their roles within the wider clinical workforce, and led to more effective team working.

Staff feedback suggests the sessions are having positive benefits; they feel they are effective and enjoyable. Encouragingly staff have begun to take ownership of the sessions, suggesting topics for discussion. We have found that since introducing the ten-minutes sharing and learning sessions team morale has improved with staff telling us they feel included and valued. We plan to continue with the sharing and learning sessions with our intention being to build on our success. They are proving to be effective in ensuring our busy clinical workforce gains the knowledge and skills required to deliver high quality care to our patients.

\section{P-54 'RESPIRATORY REFRESHER': AN IN-HOUSE TEACHING PROGRAMME TO UPSKILL COMMUNITY NURSE SPECIALISTS}

Nicola Galliford, Laura Gordge. St Barnabas House Hospice, Worthing, UK

\subsection{6/bmjspcare-2019-HUKNC.78}

Introduction Ten of the community palliative care nurses working out of St Barnabas House Hospice in Worthing have previously attended a physical examination course. Some nurses have attended this very recently, but others less so. Informal feedback from these nurses suggested they lacked confidence performing examinations in their clinical practice and needed assistance in maintaining their skills. The inpatient unit often has stable patients with respiratory signs. Many of the doctors staffing the unit have an interest in teaching and have recently passed the clinical examination for membership of the Royal College of Physicians (PACES). A teaching programme was designed to share knowledge and address educational needs of the community team.

Methods Nine of the ten nurses signed up to a programme of 6 one-hour sessions in this pilot. Each session is limited to three nurses and is run by a ward doctor on the inpatient unit. The sessions are tailored to the attending community nurse specialists' needs and involve examining patients on the inpatient ward with respiratory signs. Attendees are required to fill in a short survey before attending the first session and after attending the last session to assess their subjective confidence levels in performing the respiratory examination and finding signs. The number of examinations performed during clinical practice per week before and after the course will also be measured as an assessment of behavioural change.

Results The project is currently in progress, results to be presented at the conference.

\section{P-55 THE VOICE BEHIND THE PALLIATIVE CARE ADVICE LINE: ENSURING KNOWLEDGE, SKILLS AND SUPPORT}

Sally Bailey. Dorothy House Hospice Care, Winsley, UK

\subsection{6/bmjspcare-2019-HUKNC.79}

Background National guidelines place an emphasis on patients, carers and health professionals being able to access specialist palliative care advice at all times (National Council for Palliative Care, 2015; Department of Health, 2008). The advice line enables this timely support and guidance. However, whilst running alongside the Inpatient Unit, the specific skills and knowledge required to handle calls can be overlooked (Carr, Lhussier \& Wilcockson, 2008).

Aims To support all Registered Nurses working on the Inpatient Unit to feel more confident and competent in taking advice line calls (Purc- Stephenson \& Thrasher, 2010) delivering up to date, safe and consistent advice, whilst enabling a culture of feedback and support.

Methods

- The development of advice line training following consultation with unit staff, feedback from other hospices and literature review, with sessions balancing specific telephone communication skills alongside clinical knowledge and practical elements (Yardley, Codling, Roberts, O’Donnell et al., 2009);

- The implementation of a new framework to help guide more complex calls - encouraging staff to think of completing a jigsaw puzzle without being able to see the picture on the box, and by putting together 'pieces' of information to guide the advice given by remembering to 'delve' and 'tell me more...';

- The commencement of regular feedback sessions enabling protected time for staff to 'offload', discuss difficult calls and for feedback and ongoing teaching from an Inpatient Unit Consultant or other palliative care professional;

- The development of an information pack to accompany training and an advice line resource folder for staff to reference during calls.

Conclusion Acknowledging that for some staff the advice line can be stressful, the implementation of training and support has had a very positive impact, with staff reporting a more confident approach when taking calls. The new resources have been welcomed and already proven useful, particularly when dealing with medication related calls. This work is already enabling the delivery of more consistent, confident and quality advice and in time this will undoubtedly increase caller satisfaction (Moscato, Valanis, Gullion, Tanner et al., 2007).

\section{P-56 TEACHING NURSES TO TEACH END OF LIFE CARE: CNSS' PERCEPTIONS OF THE IMPACT OF AN EDUCATIONAL INTERVENTION}

${ }^{1,2}$ Karen Groves, ${ }^{2}$ Barbara Jack, ${ }^{2}$ Mary O'Brien. ' Queenscourt Hospice, Southport, UK; ${ }^{2}$ Edge Hill University, Ormskirk, UK

\subsection{6/bmjspcare-2019-HUKNC.80}

Background Central to national and international policies is the need for generalist healthcare staff to have education in end-of-life care. Much end-of-life care education is provided by specialist nurses who often have no specific education development to prepare them to teach. To address this gap an 